\title{
Elastomeric Polymers for Retrofitting of Reinforced Concrete Structures against the Explosive Effects of Blast
}

\author{
S. N. Raman, ${ }^{1}$ T. Ngo, ${ }^{2}$ P. Mendis, ${ }^{2}$ and T. Pham ${ }^{3}$ \\ ${ }^{1}$ Department of Architecture, Universiti Kebangsaan Malaysia, 43600 UKM Bangi, Selangor, Malaysia \\ ${ }^{2}$ Department of Infrastructure Engineering, The Univeristy of Melbourne, Melbourne, VIC 3010, Australia \\ ${ }^{3}$ Department of Civil and Industrial Construction, University of Civil Engineering, Ha Noi 100000, Vietnam
}

Correspondence should be addressed to S. N. Raman, snraman@gmail.com

Received 4 June 2012; Revised 16 August 2012; Accepted 18 August 2012

Academic Editor: Luigi Nicolais

Copyright () 2012 S. N. Raman et al. This is an open access article distributed under the Creative Commons Attribution License, which permits unrestricted use, distribution, and reproduction in any medium, provided the original work is properly cited.

\begin{abstract}
The main distinction of blast load from other types of dynamic loadings is its impulsive nature, where the loads usually act for a very short duration but transmit very high impulsive pressures. This paper presents an overview of the present retrofitting techniques in use to enhance the capacity of structural elements to withstand the effects of blast loads, and introduces an alternative retrofitting approach by utilizing polymer coatings. The authors have demonstrated the positive effects of this approach by conducting a numerical investigation on the behavior of an unretrofitted reinforced concrete panel subjected to the blast load from a $2 \mathrm{~kg}$ charge at $1.6 \mathrm{~m}$ stand-off distance, and subsequently comparing its performance with several polymer coated panels. The analysis was performed by using an explicit nonlinear finite element (FE) code. The results demonstrate the contributions of this technique in terms of panel displacement control and energy dissipation. Considering that the polymer coating can also act as a protective layer in improving the durability of structural materials, this technique can also be optimized favorably to enhance the overall sustainability of structures.
\end{abstract}

\section{Introduction}

In recent years, buildings and critical infrastructures across the globe have become more vulnerable to extreme dynamic blast and impact loads due to the increase in terrorist activities, accidental explosions, proliferation of weapons, and so forth. The losses from such events cannot be measured from the economic aspects alone since many of the target structures are iconic and carry substantial heritage, architectural, and sentimental values. While substantial efforts in architecture and structural engineering have been focused towards optimal design and construction practices to meet the desires of sustainability and sustainable development, the need to preserve and protect existing critical infrastructures to meet the needs of the future should not be disregarded. Every effort should be undertaken to preserve and protect such structures, especially for future generations.

The main distinction of blast load from other types of extreme loadings is its impulsive nature. Blast loads usually act for a very short duration (usually in milliseconds) but transmit very high impulsive pressures $\left(10^{1}-10^{3} \mathrm{kPa}\right)$. The resulting damage to the structural system can be in several forms, such as damage to the external facade and structural frames of the building; collapse of walls; blowing out of concrete fragments, glass windows and fixtures; and shutting down of critical life-safety systems. Considering that most of the existing structures are not designed to withstand such extreme dynamic loads, a comprehensive understanding of the blast phenomena and dynamic response of various structural and nonstructural elements is essential in developing a feasible structural retrofitting scheme to enhance the impulsive resistance of structures. Significant efforts have been undertaken in recent years to identify innovative structural strengthening and retrofitting applications in order to enhance the capacity of structural materials and components to withstand such extreme loadings.

In this perspective, elastomeric polymers such as polyurea and polyurethane are finding relevance in strengthening applications for structures being subjected to blast and impact loads. In many cases, these materials possess an 
elongation capacity of $100 \%$ or more and can be applied easily by just spraying onto the face of a structural element. This technique capitalizes on the elastomeric properties, high strain capacity, high ductility and strength of the polymers, as well as the ability of the coating layer to act as a shield in containing debris and fragments from the blast. Another advantage of these polymers is the possibility of customizing their chemical composition and stoichiometry by altering their underlying hard and soft domains.

This paper provides an overview of the research and existing practices in strengthening and retrofitting of structural elements to withstand the effects of blast loads, as well as the findings of a research endeavor initiated by the authors to investigate and develop a robust structural retrofitting scheme by utilizing elastomeric polymers to enhance the resistance of reinforced concrete (RC) structures to blast effects.

\section{Present Strengthening Procedures}

Recent research and practices in strengthening of structures against blast loads are focused on the utilization of composite laminates such as fiber-reinforced polymer (FRP) applications. These include carbon FRP (CFRP) and glass FRP (GFRP), which are the most common, besides aramid FRP, aramid/glass $(\mathrm{A} / \mathrm{G})$ hybrid applications, and GFRP rods. Buchan and Chen [1] and Malvar et al. [2] have undertaken comprehensive reviews and summarized the findings from researches in recent years in the area of strengthening and retrofitting of structures subjected blast effects. Most of these researches have focused on the application of FRP on concrete structures. Muszynski and Purcell [3] compared the performance of CFRP and A/G hybrid as the strengthening system against blast loading through a series of high explosive detonations on RC walls. The reduction of residual displacements of the walls was more significant when the $A / G$ hybrid was used compared to the CFRP. Meanwhile, Tolba [4] researched the ultimate resistance and structural behavior of RC panels externally bonded with FRP sheets and strips, subjected to blast effects. CFRP and E-glass were chosen as the strengthening materials. The outcome generally indicated that the performance of FRP strengthened panels was superior to ordinary RC panels in terms of structural integrity and capability to withstand blast pressure [4].

More recently, Tanapornraweekit [5] undertook a comprehensive study to investigate the behavior of FRP strengthened RC slabs under blast loadings. This study involved twelve explosion tests on nine RC slabs using various types (CFRP and GFRP) and configurations of FRP strengthening. Some of the strengthened RC slabs were subjected to more than one independent explosion. The findings of these blast experiments suggested that while the single-sided FRP was able to strengthen the RC slabs, it was less effective when compared to the FRP sandwich scheme. The RC slabs with FRP sandwich strengthening scheme offered a higher level of protection and were also able to resist the effects from a second explosion [5-7].
FRP strengthening has also shown beneficial effects on masonry walls. In the investigation by Muszynski and Purcell [3], CFRP strengthening was able to significantly reduce the displacement of the wall when compared to the control wall.

Other retrofitting techniques that have shown favorable outcomes in blast protection include steel plating and jacketing, and geotextile fabric applications. Remennikov and Carolan [8] discussed the application of using geotextile fabrics, typically woven polypropylene, to act as a buffer to the masonry wall debris and fragments from being propelled and becoming a hazard to the occupants of the building. However, this technique does not enhance the strength capacity of the wall [8].

Though the research on strengthening applications for structural elements subjected to blast and impact loadings has been undertaken for more than a decade, there is yet to be any specific technique or material established to be considered as primarily suitable for retrofitting of structures against blast effects. A similar observation was shared by Buchan and Chen, who also suggested that a more systematic direction is required to determine the advantages and limitations of the various strengthening applications [1]. While FRP has been indicated to be a potential solution, its widespread application in practice is usually restricted by its relatively higher initial costs in terms of materials and expertise, lower time efficiency, and the challenges associated with its practical installation to existing structures.

In some instances, the excessively thin sheets of the material may require an impractical number of layers or wraps on the structure to function effectively under impulsive loading conditions. Besides, in cases of close-in detonations, the strain demand of the strengthening material is beyond the strain capacity of FRP [2], deeming it to be unsuitable for such load cases. The use of steel jacketing might also be unsuitable in this situation, since the welds near the threat may fail prematurely [2]. FRP strengthening can also lead to a premature brittle failure, such as through FRP debonding and FRP-concrete cover delamination.

\section{Elastomeric Polymers for Structural Retrofitting}

One of the limiting factors in the performance of composite laminates such as FRP and other retrofitting materials is the material's low failure strains. This characteristic plays a more significant role in cases of high strain rate impulsive loadings. An alternative approach of using elastomeric polymers may well become a potential solution to this problem. These materials, specifically polyurea and polyurethane, may possess an elongation capacity of $100 \%$ or more and can be applied easily by spraying onto the face of the structure. The following sections provide an overview of the research undertaken and the application of this innovative retrofitting technique on structures being subjected to blast effects.

3.1. Application on Masonry Structures. The Air Force Research Laboratory (AFRL) at Tyndall Air Force Base, USA, began experimenting with sprayed-on polymers in 1999, 
initially using a commercially available spray-on truck bed liner. The material was tested on unreinforced masonry walls. The success from the initial testing led to the evaluation of another 21 off-the-shelf polymers to identify the most suitable material for further testing programs. A spray-on pure polyurea was selected based on its strength, flammability, and cost, to undergo further testing to evaluate its performance under blast effects [9-11].

Three full-scale explosive tests were conducted in the first phase of the study. One reaction structure consisting of two unreinforced masonry walls was constructed for each test, except for the third test where four walls were evaluated. The findings indicated that the application of polyurea coatings on the interior face of the walls was able to increase their resistance to the blast effects, as well as to contribute towards fragmentation prevention. While the application of polyurea on both sides of the wall did enhance the capacity of the wall against the loads, it was deemed inadequate to address the extra cost [10]. In the subsequent study, seven explosive tests were undertaken involving a total of 12 polymer coated masonry walls, which included four walls with a window or a door opening. In addition to the experimental tests, finite element (FE) analysis of the walls' behavior was undertaken using DYNA3D in order to allow for better understanding of the failure and fracture mechanisms. The authors concluded that in the selection of the retrofitting material, consideration should be given to both stiffness and elongation properties of the material, with key consideration to the elongation capacity [11].

Meanwhile, Baylot et al. [12] evaluated three types of retrofitting applications on quarter-scale models of typical $203 \mathrm{~mm}$ concrete masonry unit (CMU) walls. The first consisted of $1 \mathrm{~mm}$ thick E-glass FRP attached to the back face of the wall, and the second type consisted of a two-part sprayed on polyurea coating on the back face of the wall, with an approximate thickness of $3.2 \mathrm{~mm}$. In the third option, a $1 \mathrm{~mm}$ thick hot-dipped galvanized steel sheet was attached to the back of the wall. Although all the retrofitted walls failed during the tests, the polyurea coating and the FRP were successful in containing the fragments and debris inside the structure [12].

These findings clearly indicate the benefits of using this technique to retrofit masonry structures against the effects of blast loads, especially in terms of fragmentation prevention. Considering the ease of application of this technique and its capability in reducing the vulnerability of masonry structures to blast loads, this technique can be optimized favorably to protect heritage structures.

3.2. Application on Steel Structures. More recently, polymer coatings have also been researched for the purpose of strengthening steel structures. Amini et al. $[13,14]$ reported the findings of experimental work undertaken to assess the effect of polyurea coating on the dynamic response of steel plates, through a newly developed test known as the reverse ballistic test. The primary focus of their study was on the significance of the coating location with respect to the loading direction, that is, either coating on the loaded face or the unloaded face of the plates, in order to impart optimal blast protection. It was established that the polyurea coating would result in positive outcomes, both in terms of failure mitigation and energy absorption, only when it is applied on the back face or the unloaded face of the plate. The authors also indicated that the application of the coating on the blast-receiving face of the plate would in turn increase the destructive effect of the blast, thus elevating the damage of the steel plate $[13,14]$.

Meanwhile, both experimental and numerical findings from the research conducted by the Defence Science and Technology Organisation of Australia (DSTO) established that the polymer coating improved the blast resistance of the steel plates, where the polymer coated plates recorded much lower permanent deformation compared to the bare plate. Besides, the plate that was coated with a thicker polyurea layer indicated much lower deformation compared to the plate coated with a thin layer of polyurea coating [15].

\section{Application of Polymer Coatings on Reinforced Concrete Structures}

While this technique has been investigated and indicated positive findings on other structural materials, its application on concrete structures has not been investigated comprehensively. In RC and other concrete structures, the coatings can also function as a protective layer to the structural materials (concrete and reinforcements/strands) from aggressive environmental impacts, thus contributing towards the overall durability and sustainability of the structure. The following sections present the description and findings of the numerical analysis of the progressive research endeavor undertaken by the authors to investigate the feasibility of using polymer coatings to retrofit RC structures under the effects of blast.

4.1. Finite Element Model Development. The numerical analysis was performed using LS-DYNA nonlinear explicit FE code [16]. The specimen that was investigated was a $60 \mathrm{~mm}$ thick slab-like RC panel with dimensions of $1000 \times 1700 \mathrm{~mm}$. The panel was constructed with $40 \mathrm{MPa}$ concrete and was reinforced in the bottom (tension) face only with $5 \mathrm{~mm}$ bars at $100 \mathrm{~mm}$ spacing in both directions. The nominal yield stress of the reinforcement was $500 \mathrm{MPa}$. The panels were connected to the test frame using a $100 \times 100 \times 10 \mathrm{~mm}$ steel cleat, and seven $\varnothing 14$ bolts, and seven $\varnothing 25$ bolts, at each support. The yield stresses of the steel bolts and cleats were $660 \mathrm{MPa}$ and $300 \mathrm{MPa}$, respectively. The connection details and the support mechanism of the panels are illustrated in Figure 1. The behavior of one unretrofitted panel (Bare) and six polyurea coated panels (see Table 1) was modeled and analyzed in this study. Polyurea coatings were applied on all the retrofitted panels but the coating thicknesses and locations (surface) of application were varied, as summarized in Table 1. The panels were subjected to a spherical air blast from a $2 \mathrm{~kg}$ TNT equivalent charge at $1.6 \mathrm{~m}$ stand-off distance. 

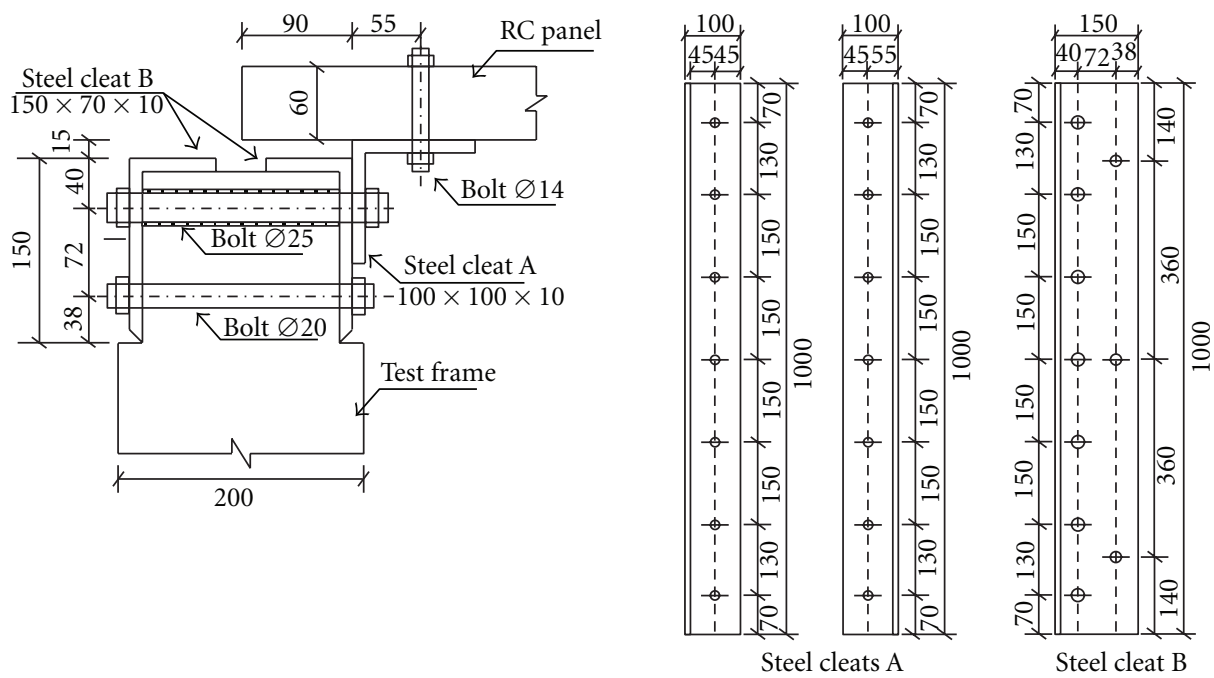

FIGURE 1: Details of connections between the panel and the test frame.

TABLE 1: Location of application of polyurea coating on each panel.

\begin{tabular}{lcc}
\hline Panel designation & \multicolumn{2}{c}{ Polyurea coating on } \\
& $\begin{array}{c}\text { Top surface } \\
\text { (blast-receiving face) }\end{array}$ & Bottom surface \\
\hline Bare & - & - \\
PUB4 & - & $4 \mathrm{~mm}$ \\
PUB8 & - & $8 \mathrm{~mm}$ \\
PUT4 & $4 \mathrm{~mm}$ & - \\
PUT8 & $8 \mathrm{~mm}$ & - \\
PUTB4 & $4 \mathrm{~mm}$ & $4 \mathrm{~mm}$ \\
PUTB8 & $8 \mathrm{~mm}$ & $8 \mathrm{~mm}$ \\
\hline
\end{tabular}

4.2. Elements, Constitutive Models, and Contact Options. Existing constitutive models in LS-DYNA were adopted to model the different materials of the structural system. The concrete elements were modeled with eight-noded solid elements using the MAT_CONCRETE_DAMAGE_REL3 constitutive model. This material model incorporates damage and strain rate effects, as well as the capability for model parameter generation based on the compressive strength of concrete [16, 17]. The longitudinal and transverse reinforcements were modeled with MAT_PIECEWISE_ LINEAR_PLASTICITY using three-noded Hughes-Liu beam elements. The dynamic increase factor (DIF) at high strain rates for yield and ultimate stress of steel was based on Malvar [18].

The polyurea coatings were modeled as four-noded shell elements, using the MAT_PIECEWISE_ LINEAR_PLASTICITY material model. The quasi-static and high strain rate properties of polyurea were adopted from Bahei-El-Din and Dvorak [19]. MAT_PIECEWISE_ LINEAR_PLASTICITY allows for rate effects to be included by defining a table of curves, specifying the stress-strain curves for different strain rates. The shell elements were offset from the surface of the concrete panel to be located

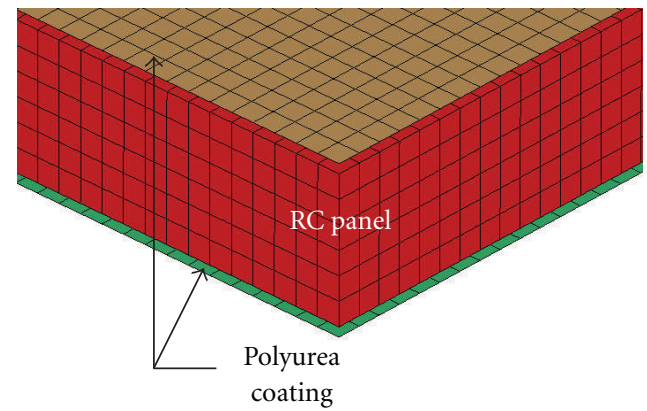

Figure 2: A section of panel PUTB8. at the mid-point of the coating thickness, that is, for the $4 \mathrm{~mm}$ coating, the shell elements were offset $2 \mathrm{~mm}$ from the concrete panel, and similarly, the shell elements were offset by $4 \mathrm{~mm}$ from the panel with the $8 \mathrm{~mm}$ coating. Figure 2 shows a section of panel PUTB8, indicating the concrete panel and both layers of polyurea coating.

The steel cleats connecting the panel to the test frame were modeled by using eight-noded solid elements. The cleats were secured to the panel and the test frame by using bolts. Each steel bolt was modeled using four beam elements. Considering the isotropic nature of the materials, both the steel cleats and bolts were modeled with MAT_PLASTIC_KINEMATIC material model. The test frame was represented by two blocks at both ends of the panel, acting as supports to the structural system in the FE model. The blocks were modeled with eight-noded solid elements by using MAT_RIGID material model.

The interface between the concrete panel and the steel cleat, and the steel cleat and the rigid block (test frame) was defined using the CONTACT AUTOMATIC_SURFACE_TO_SURFACE algorithm, available in LS-DYNA [16]. This arrangement permits contact between the panel and the cleat, and the cleat and the test frame to be tied only at the location 


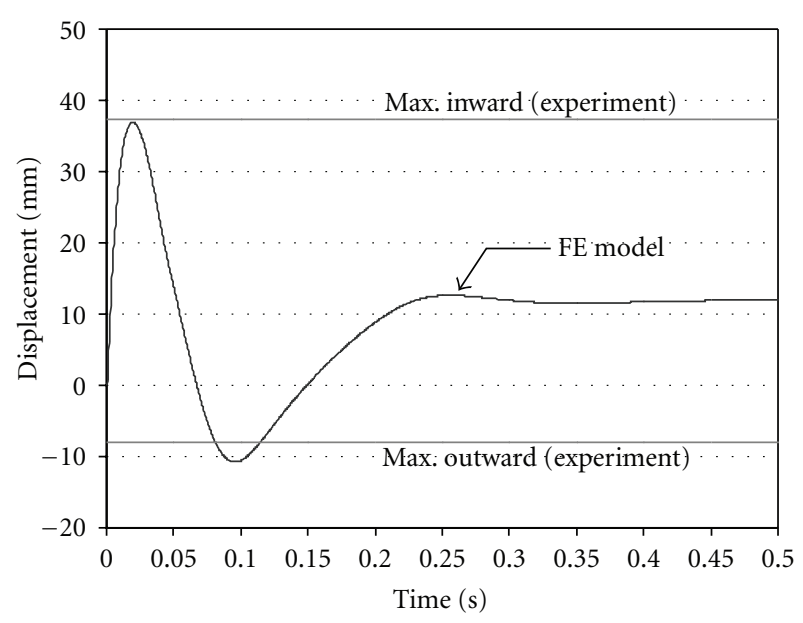

Figure 3: Comparison between deflections recorded from the experiment and the FE modeling exercise of the unretrofitted panel tested during Vietnam Trial 2.

of the bolts. Meanwhile, the interface between the concrete panel and the polyurea coatings were defined using the CONTACT_TIED_SURFACE_TO_SURFACE_OFFSET algorithm, considering that the bond slip behavior of the polyurea coatings will not be dominant. The blast pressures were computed in the analysis by using the CONWEP code [20].

4.3. Calibration of Finite Element Model. The developed FE models, especially the boundary conditions and the support system, were calibrated by using the results from one of the panel tested during Vietnam Trial 2, undertaken in 2010. The selected panel was an unretrofitted panel which had similar dimensions $(1700 \times 1000 \times 60 \mathrm{~mm})$ and was constructed with similar material properties as the panels modeled in this study. However, unlike the present support system described in Section 4.1 which was formed using seven $\varnothing 14$ bolts and seven $\varnothing 25$ bolts, the calibrated panel was supported onto the test frame using a $100 \times 100 \times 10 \mathrm{~mm}$ steel cleat, and nine $\varnothing 20$ bolts and another nine $\varnothing 20$ bolts, at each support.

During the experimental trials, the panel was subjected to a spherical air blast from the detonation of $1.0 \mathrm{~kg}$ Ammonite charge placed at $1.0 \mathrm{~m}$ stand-off distance. The central mid-span displacement of specimen was determined using mechanical displacement measurement devices. The performance and accuracy of the device was already validated with a linear variable differential transformer (LVDT) system during Vietnam Trial 1, which was conducted in 2009 [21]. The maximum inward (downward) displacement and outward displacement (rebound) recorded in the experiment was $37.7 \mathrm{~mm}$ and $7.9 \mathrm{~mm}$, respectively (Figure 3 ). The panel also recorded a permanent (downward) deflection of $19.2 \mathrm{~mm}$.

The FE model of the unretrofitted panel was developed using the similar configuration as the present study. The maximum inward and outward (rebound) displacements determined from this modelling exercise was $36.9 \mathrm{~mm}$ and
TABLE 2: Maximum and permanent displacements recorded in the panels due to the blast load.

\begin{tabular}{lcc}
\hline Panel designation & \multicolumn{2}{c}{ Displacement $(\mathrm{mm})$} \\
\hline Bare & 39 & Permanent \\
PUB4 & 23 & 18 \\
PUB8 & 20 & 9 \\
PUT4 & 32 & 4 \\
PUT8 & 26 & 13 \\
PUTB4 & 20 & 5 \\
PUTB8 & 15 & 7 \\
\hline
\end{tabular}

$10.8 \mathrm{~mm}$, respectively, as shown in Figure 3. The permanent (downward) deflection recorded in the FE model was $12.0 \mathrm{~mm}$. These findings agree satisfactorily with the corresponding values recorded during the experiment.

\section{Results and Discussion}

The panels modeled in the present study were subjected to blast load from the detonation of a $2 \mathrm{~kg}$ TNT equivalent charge at $1.6 \mathrm{~m}$ stand-off distance (Figure 4). The peak reflected pressure and impulse from the blast, as computed from the CONWEP code [20], were $2477 \mathrm{kPa}$ and $518.2 \mathrm{kPa}$ $\mathrm{ms}$, respectively, at an arrival time of $1.05 \mathrm{~ms}$. This dynamic load caused a maximum displacement of $39 \mathrm{~mm}$ in the unretrofitted panel (Bare). Figure 4 illustrates the deflected profile and damage contour of the unretrofitted panel, whereas the inset shows the blast-reflected pressure-time history as computed from the CONWEP code [20].

Table 2 summarizes the displacement findings from the FE analyses for the unretrofitted panel (Bare) and various polyurea coated panels, whereas Figure 5 provides the comparisons of displacement-time histories of these panels. From Table 2 and Figure 5, it can be deduced that the polyurea coatings contribute significantly in controlling the displacement of the panels. By applying a $4 \mathrm{~mm}$ coating layer (about 7\% of the panel thickness) at the bottom (non-blastfacing) face of the panel (in PUB4), both the maximum and permanent displacements of the panel were reduced by more than $40 \%$. One of the contributing factors may be the ability of the polyurea coating to absorb the high kinetic energy dissipated during the blast, which consequently results in reduced displacement.

Increasing the thickness of the polyurea coating does not seem to contribute significantly in reducing the displacement further when compared to the thinner coating. It was also noticed that the application of a polyurea coating on the non-blast-facing (tension) face of the panel tends to be more effective in terms of displacement control. Nonetheless, the application of the coating on the blast-facing face or on both surfaces of a structure may contribute in terms of energy absorption of the system. Further, in terms of practicality, it may be more "straightforward" to apply the retrofitting coating on the outer (blast-receiving) surface of a structure. While applying the coatings on both faces of the panel 


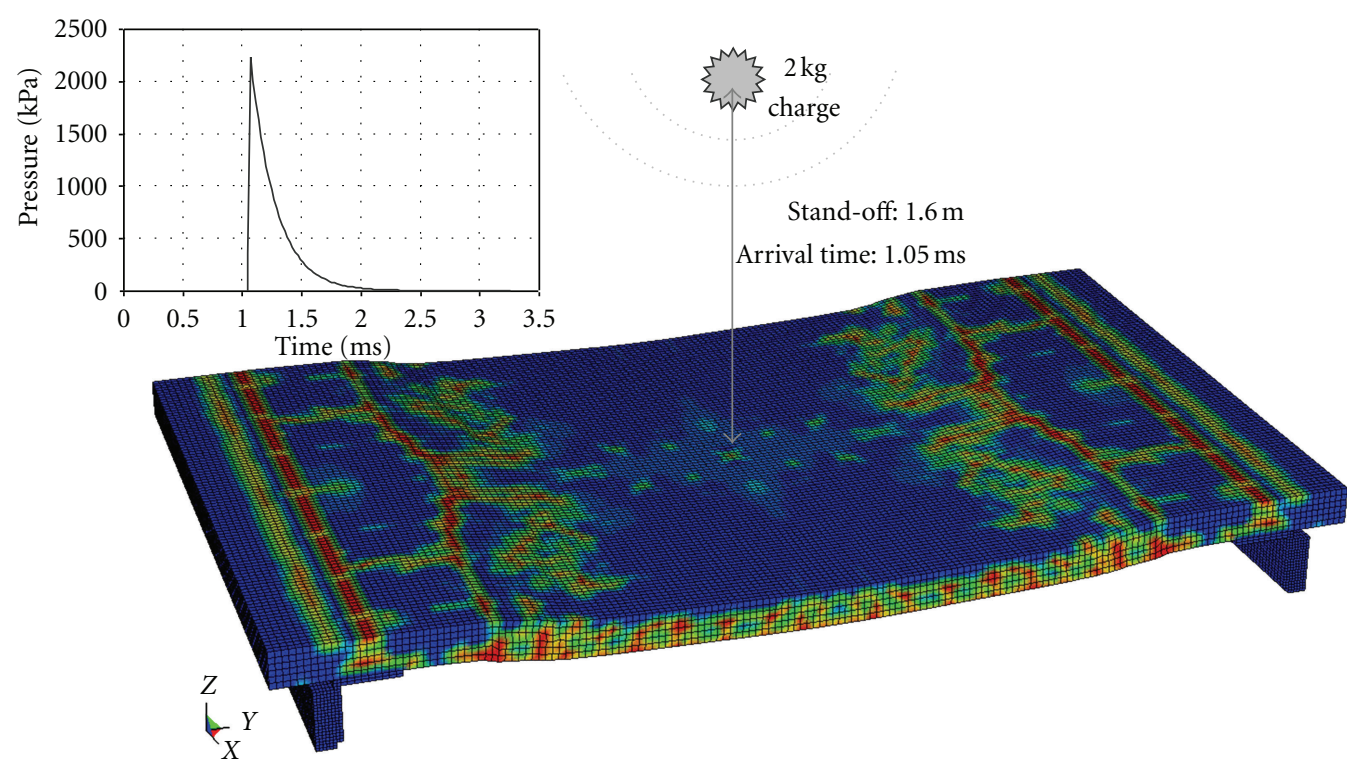

FIGURE 4: The deflected profile and damage contour of the unretrofitted (Bare) panel due to the blast load. Inset: Blast reflected pressure-time history.

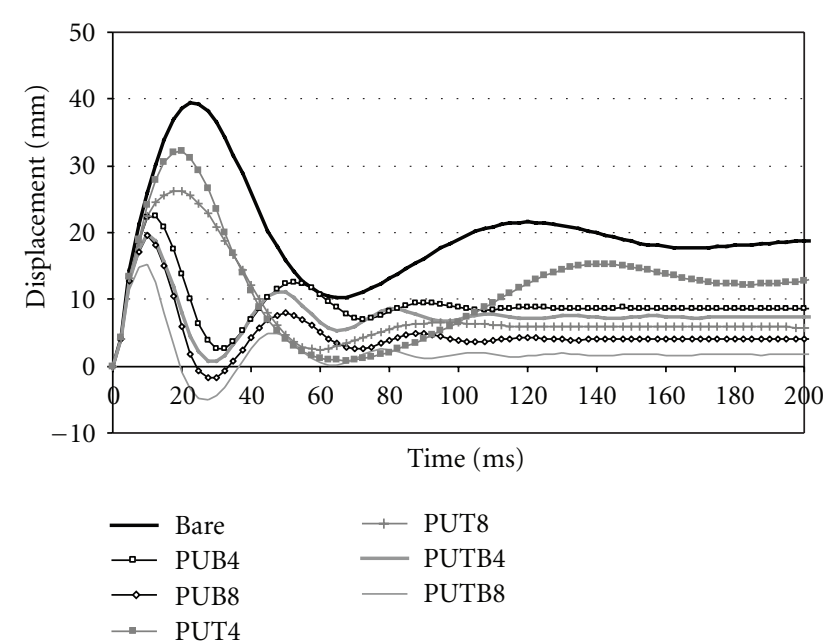

FIGURE 5: Displacement-time histories of the bare panel and various polyurea coated panels.

appears to have further enhanced the performance of the panel, these double-coating applications may not be justified in terms of cost and time efficiency.

The energy dissipated onto a structure during a blast is converted into strain and kinetic energies. While the strain energy is accumulated by the elastic components of the structure as their internal energy, the kinetic energy results in the movement of components of the structural system [19], which in this case are concrete, reinforcements, polyurea layers, and the support systems. The plot of peak kinetic energy in concrete and reinforcements as obtained from the FE analysis for the unretrofitted and selected retrofitted panels is shown in Figure 6. It is evident that the use of polyurea coatings on the panels facilitates in the energy

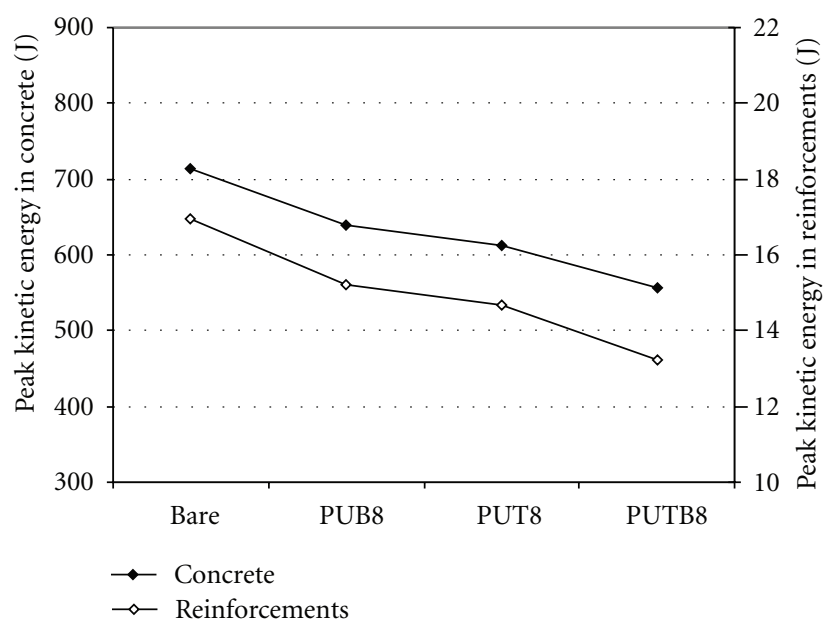

Figure 6: Peak kinetic energy in concrete and reinforcements of selected panels.

absorption of the system, and subsequently in enhancing the blast resistance of the panels. It is also evident that the application of the coating on the blast-receiving face of the panel contributes more significantly in this aspect.

Meanwhile, Figure 7 illustrates the contours of damage profiles on the bottom surfaces of selected concrete panels. The damage ranges from 0 to 2 (as indicated in the fringe levels) corresponding to the progression through the three failure surfaces, that is, initial yield surface, maximum failure surface, and residual failure surface, in the MAT_CONCRETE_DAMAGE_REL3 constitutive model [16]. The contours of damage indicate that the crack densities were more severe in the transverse direction, especially in the Bare and PUT4 panels. Some damage reductions 


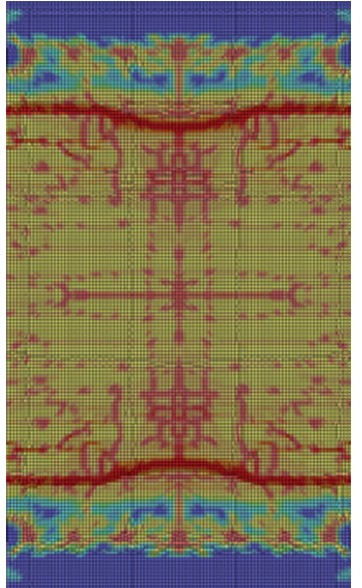

(a) Bare

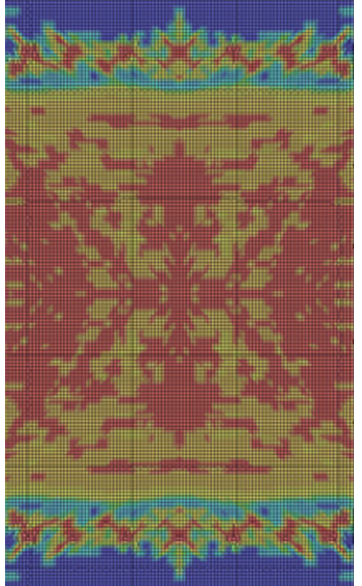

(b) PUB4

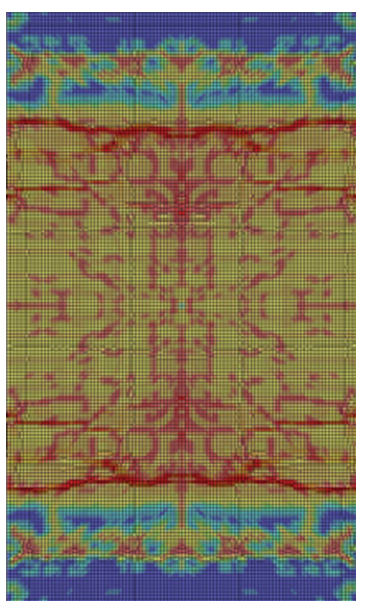

(c) PUT4

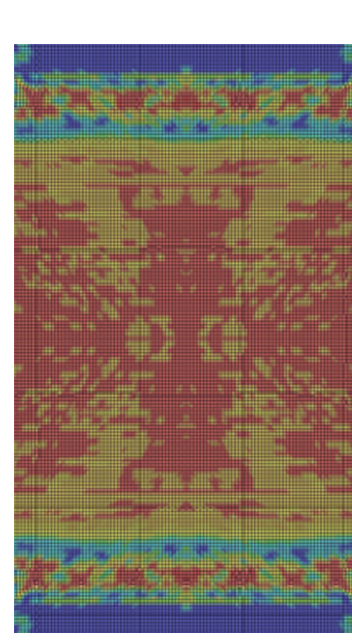

(d) PUTB4

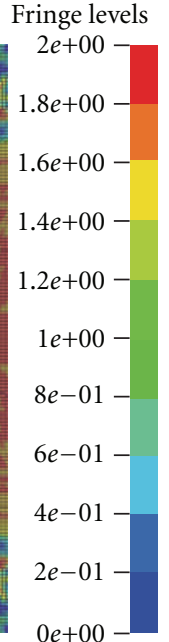

Figure 7: Contours of damage to the concrete elements on the bottom face of selected panels. were observed in the concrete elements due to the polyurea coatings and it was also noticed that the polyurea coatings were intact without any tearing after the application of the loads. The intactness of the coatings indicates that it would be able to shield the spalled concrete debris and fragments from propelling.

These findings clearly indicate the positive contributions and the effectiveness of this innovative technique in retrofitting concrete structures being subjected to the risk of blast loads. Besides, the coatings would also be able to act as a shield in minimizing spalled concrete debris and fragments from being propelled, as well as in contributing towards the durability of the structure as a whole.

\section{Conclusions}

This paper presented an overview of the present retrofitting techniques in use to enhance the capacity of structural elements to withstand the effects of blast loads, and also introduced an alternative approach for retrofitting structures by using elastomeric polymer coatings. Recent research findings on the application of this technique on masonry and steel structures were discussed. Subsequently, the findings of a nonlinear FE analysis performed by the authors to evaluate the effectiveness of polyurea coatings in retrofitting concrete panels subjected to blast load were discussed. The findings demonstrate the contribution of the polyurea coatings in terms of panel displacement control and energy dissipation. This technique can be adopted favorably to protect structures due to its capability in reducing the vulnerability of structures to blast loads.

\section{Acknowledgment}

This work was performed during the Ph.D. candidature of S. N. Raman at The University of Melbourne, Australia.
The scholarship provided by the Ministry of Higher Education, Malaysia, and Universiti Kebangsaan Malaysia is duly acknowledged.

\section{References}

[1] P. A. Buchan and J. F. Chen, "Blast resistance of FRP composites and polymer strengthened concrete and masonry structures-a state-of-the-art review," Composites Part B: Engineering, vol. 38, no. 5-6, pp. 509-522, 2007.

[2] L. J. Malvar, J. E. Crawford, and K. B. Morrill, "Use of composites to resist blast," Journal of Composites for Construction, vol. 11, no. 6, pp. 601-610, 2007.

[3] L. C. Muszynski and M. R. Purcell, "Use of composite reinforcement to strengthen concrete and air-entrained concrete masonry walls against air blast," Journal of Composites for Construction, vol. 7, no. 2, pp. 98-108, 2003.

[4] A. Tolba, Response of FRP-retrofitted reinforced concrete panels to blast loading [Ph.D. thesis], Charleton University, Ottawa, Canada, 2001.

[5] G. Tanapornraweekit, Behaviour of fibre reinforced polymer (FRP) strengthened RC slabs subjected to blast loading [Ph.D. thesis], Department of Civil and Environmental Engineering, The University of Melbourne, Melbourne, Australia, 2010.

[6] G. Tanapornraweekit, N. Haritos, P. Mendis, and T. Ngo, "Finite element simulation of FRP strengthened reinforced concrete slabs under two independent air blasts," International Journal of Protective Structures, vol. 1, no. 4, pp. 469-488, 2010.

[7] G. Tanapornraweekit, N. Haritos, T. Ngo, and P. Mendis, "Behaviour of FRP-RC slabs under two independent air blasts," in Proceedings of the 8th International Conference on Shock and Impact Loads on Structures, pp. 609-618, Adelaide, Australia, 2009.

[8] A. Remennikov and D. Carolan, "High performance retrofit solutions for blast protection of facades in office buildings," in Proceedings of the RNSA Security Technology Conference, pp. 44-54, Melbourne, Australia, 2007.

[9] K. J. Knox, M. I. Hammons, T. T. Lewis, and J. R. Porter, Polymer Materials for Structural Retrofit, Florida: Force Protection 
Branch, Air Expeditionary Forces Technology Division, Air Force Research Laboratory, Tyndall AFB, 2007.

[10] J. S. Davidson, J. R. Porter, R. J. Dinan, M. I. Hammons, and J. D. Connell, "Explosive testing of polymer retrofit masonry walls," Journal of Performance of Constructed Facilities, vol. 18, no. 2, pp. 100-106, 2004.

[11] J. S. Davidson, J. W. Fisher, M. I. Mammons, J. R. Porter, and R. J. Dinan, "Failure mechanisms of polymer-reinforced concrete masonry walls subjected to blast," Journal of Structural Engineering, vol. 131, no. 8, pp. 1194-1205, 2005.

[12] J. T. Baylot, B. Bullock, T. R. Slawson, and S. C. Woodson, "Blast response of lightly attached concrete masonry unit walls," Journal of Structural Engineering, vol. 131, no. 8, pp. 1186-1193, 2005.

[13] M. R. Amini, J. B. Isaacs, and S. Nemat-Nasser, "Effect of polyurea on the dynamic response of steel plates," in Proceedings of the SEM Annual Conference and Exposition on Experimental and Applied Mechanics, pp. 1323-1326, St. Louis, Mo, USA, June 2006.

[14] M. R. Amini, J. B. Isaacs, and S. Nemat-Nasser, "Experimental investigation of response of monolithic and bilayer plates to impulsive loads," International Journal of Impact Engineering, vol. 37, no. 1, pp. 82-89, 2010.

[15] K. Ackland, C. Anderson, and N. St John, "Polymeric coatings for enhanced protection of structures from the explosive effects of blast," in Proceedings of the RNSA Security Technology Conference, pp. 90-96, Melbourne, Australia, 2007.

[16] LS-DYNA, "LS-DYNA Keyword User's Manual, Version 971," 2007, Livermore Software Technology Corporation (LSTC), Livermore, Calif, USA.

[17] J. E. Crawford and L. J. Malvar, "User's and Theoretical Manual for K\&C Concrete Model,” K\&C Technical Report TR06-19.1, Karagozian \& Case, Burbank, Calif, USA, 2006.

[18] L. J. Malvar, "Review of static and dynamic properties of steel reinforcing bars," ACI Materials Journal, vol. 95, no. 5, pp. 609-616, 1998.

[19] Y. A. Bahei-El-Din and G. J. Dvorak, "Wave propagation and dispersion in sandwich plates subjected to blast loads," Mechanics of Advanced Materials and Structures, vol. 14, no. 6, pp. 465-475, 2007.

[20] D. W. Hyde, CONWEP-Conventional Weapons Effects Programme, USAEWES, 1992.

[21] T. T. Pham, Behaviour of reinforced concrete panels and their fixing assemblies subject to blast loading [Ph.D. thesis], Department of Civil and Environmental Engineering, The University of Melbourne, Melbourne, Australia, 2010. 

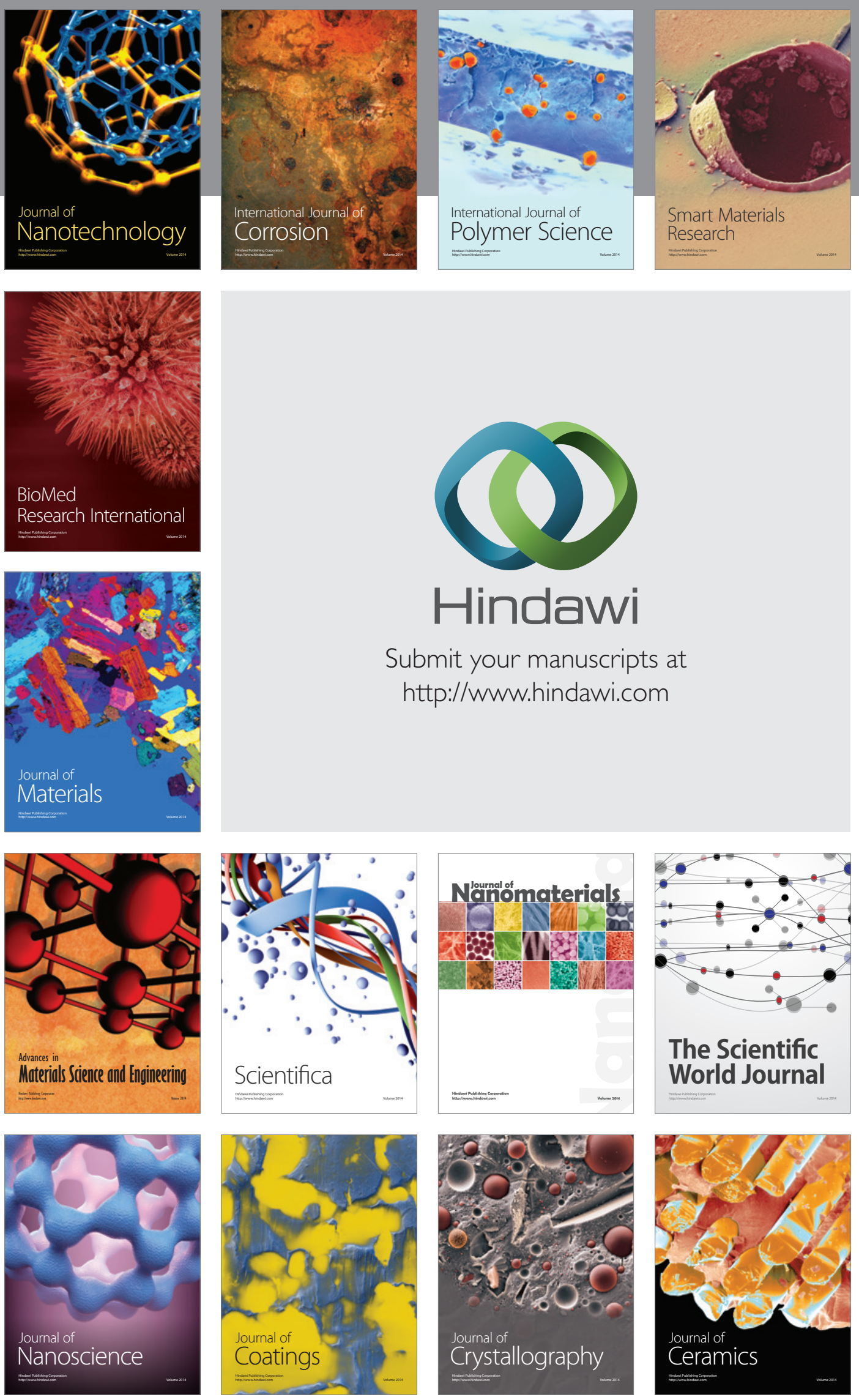

The Scientific World Journal

Submit your manuscripts at

http://www.hindawi.com

\section{World Journal}

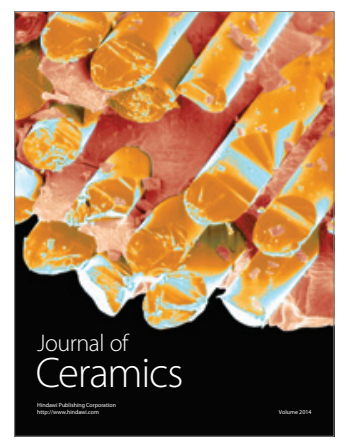

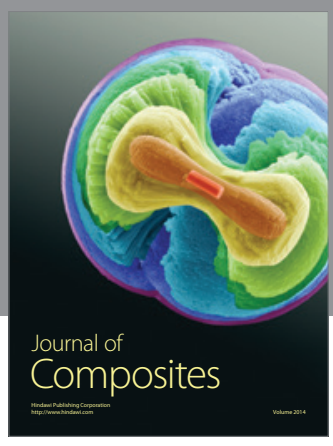
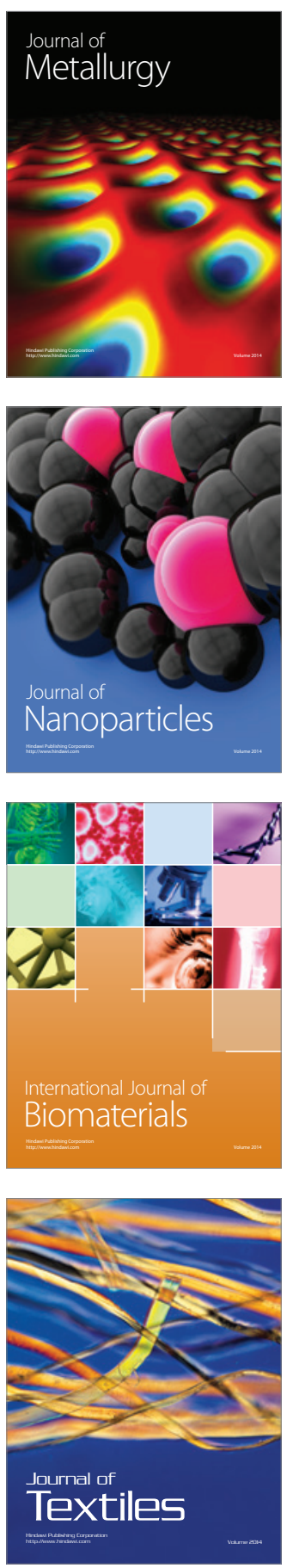